\title{
Odorant-induced Oscillations in the Mushroom Bodies of the Locust
}

\author{
Gilles Laurent and Mohammad Naraghi ${ }^{a}$ \\ California Institute of Technology, Biology Division, Pasadena, California 91125
}

Kenyon cells are the intrinsic interneurons of the mushroom bodies in the insect brain, a center for olfactory and multimodal processing and associative learning. These neurons are small (3-8 $\mu \mathrm{m}$ soma diameter) and numerous $(340,000$ and 400,000 in the bee and cockroach brains, respectively). In Drosophila, Kenyon cells are the dominant site of expression of the dunce, $D C O$, and rutabaga gene products, enzymes in the CAMP cascade whose absence leads to specific defects in olfactory learning. In honeybees, the volume of the mushroom body neuropils may depend on the age or social status of the individual.

Although the anatomy of these neurons has been known for nearly a century, their physiological properties and the principles of information processing in the circuits that they form are totally unknown. This article provides a first such characterization. The activity of Kenyon cells was recorded in vivo from locust brains with intracellular and local field potential electrodes during olfactory processing. Kenyon cells had a high input impedance ( $\sim 1 \mathrm{G} \Omega$ at the soma). They produced action potentials upon depolarization, and consistently showed spike adaptation during long depolarizing current pulses. They generally displayed a low resting level of spike activity in the absence of sensory stimulation, despite a large background of spontaneous synaptic activity, and showed no intrinsic bursting behavior.

Presentation of an airborne odor, but not air alone, to an antenna evoked spatially coherent field potential oscillations in the ipsilateral mushroom body, with a frequency of $\sim 20$ $\mathrm{Hz}$. The frequency of these oscillations was independent of the nature of the odorant. Short bouts of oscillations sometimes occurred spontaneously, that is, in the absence of odorant stimulation. Autocorrelograms of the local field potentials in the absence of olfactory stimulation revealed small peaks at $\pm 50 \mathrm{msec}$, suggesting an intrinsic tendency of the mushroom body networks to oscillate at $20 \mathrm{~Hz}$. Such oscillatory behavior could not be seen from local field potential recordings in the antennal lobes, and may thus be generated in the mushroom body, or via feedback interactions with downstream neurons in the protocerebrum.

\footnotetext{
Received Aug. 19, 1993; revised Nov. 11, 1993; accepted Nov. 24, 1993.

This work was supported by. Scholarships from the McKnight and Searle/Chicago Community Trust Foundations to G.L., who is a NSF Presidential Faculty Fellow. We are grateful to Drs. James Bower, John Hopfield, Christof Koch, Mark Konishi, Henry Lester, Terrence Sejnowski, Harald Wolf, and two anonymous referees for discussion or comments on the manuscript, and to Dr. H.-J. Pflüger for the gift of a Bodian stain of a locust brain.

Correspondence should be addressed to Gilles Laurent, California Institute of Technology, Biology Division, 139-74, Pasadena, CA 91125.

${ }^{3}$ Present address: Max-Planck-Institut für biophysikalische Chemie, 3400 Göttingen, Germany.

Copyright (C) 1994 Society for Neuroscience $0270-6474 / 94 / 142993-12 \$ 05.00 / 0$
}

During the odor-induced oscillations, the membrane potential of Kenyon cells oscillated around the resting level, under the influence of excitatory inputs phase-locked to the field activity. Each phasic wave of depolarization in a Kenyon cell could be amplified by intrinsic excitable properties of the dendritic membrane, and sometimes led to one action potential, whose timing was phase-locked to the population oscillations. Such oscillations were replaced by a sustained depolarization when air alone was presented to the antenna, providing a mechanical but no olfactory stimulus. As in vertebrate and Limax olfactory and associative networks, olfactory processing in insects appears to involve correlated activity of large assemblies of neurons. The oscillations may facilitate synchrony among Kenyon cells and connected neurons and thereby facilitate learning.

[Key words: olfaction, dendritic spines, learning, Kenyon cell, invertebrate, insect]

Recent genetic, biochemical, and molccular investigations of learning in Drosophila melanogaster have identified the mushroom bodies (or corpora pedunculata, a bilaterally symmetrical neuropil of the protocerebrum) as the dominant site of expression of several metabolic enzymes in the cAMP pathway in the brain (Livingstone et al., 1984; Nighorn et al., 1991; Han et al., 1992; Levin et al., 1992; Davis, 1993). The best characterized of these enzymes, a cAMP-specific phosphodiesterase (PDE; dunce gene), a $\mathrm{Ca}^{2+} /$ calmodulin-responsive adenylyl cyclase ( $\mathrm{AC}$; rutabaga gene), and a catalytic subunit of protein kinase $\mathrm{A}(D C O$ gene), are specifically expressed by the intrinsic interneurons (the Kenyon cells) whose neurites form the mushroom body neuropils. The reduced expression of these genes in Drosophila mutants leads to the deficits in associative olfactory learning that were originally exploited for genetic dissection (see Dudai et al., 1976; Dudai, 1988). These molecular studies now tie up with a century of behavioral, anatomical, and clcctrophysiological work in this and other insects, that already identified the mushroom bodies as a probable association (multimodal) and learning center (see, e.g., Homberg, 1984; Schildberger, 1984; Heisenberg et al., 1985; Erber et al., 1987; Menzel, 1987; Kanzaki et al., 1989; Mauelshagen, 1993). In honeybees, for example, cooling of the $\alpha$-lobes or calyces of the mushroom bodies shortly after one-trial conditioning leads to a decreased conditioning response in later tests. Moreover, recent anatomical work in honeybees showed that structural changes in the mushroom bodies could be correlated with foraging experience. It was found that the ratio of volume occupied by Kenyon cell somata to that occupied by Kenyon cell neuropil decreased (thus possibly suggesting a proliferation of Kenyon cell arbor) from $1 \mathrm{~d}$ old to nurse 10 foraging individuals in a same colony (Withers et al., 1993). Many of the anatomical and behavioral investigations 
on the mushroom bodies have been carried out in the context of olfactory processing and learning, for the mushroom bodies are the main target neuropil of olfactory projection interneurons that originate in the glomerular antennal lobes (Christensen and Hildebrand, 1987; Masson and Mustaparta, 1990). The mushroom bodies of insects are therefore the second principal relay for olfactory signals, and occupy a position that is analogous, in the olfactory pathway, to that of the piriform cortex in mammals. It is not clear whether major feedback pathways exist between the mushroom bodies and the antennal lobes [as they do between piriform cortex and olfactory bulb (Haberly, 1985)], although anatomical studies indicate the existence of projections between $\alpha$ lobe of the mushroom body and antennal lobes (Arnold et al., 1985; Rybak and Menzel, 1993).

Although the morphological organization of the insect mushroom bodies and the anatomical structure of their component neurons have been known for a very long time from anatomical studies (Kenyon, 1896; Pearson, 1971; Schürmann, 1974; Mobbs, 1982; Boeckh and Ernst, 1987), the physiological properties of the Kenyon cells (i.e., the neurons that may be the site for synaptic plasticity and association of olfactory and other signals) are still unknown. An explanation for this deficiency probably lies in the small size of their somata (3-8 $\mu \mathrm{m}$, making intracellular penetration difficult) and in their tight oxygen requirements. This lack of physiological knowledge was the motivation for this investigation. We focus here on the processing of olfactory signals by Kenyon cells in the locust brain.

\section{Materials and Methods}

The preparation. All experiments were carried out with adult locusts (Schistocerca americana) of both sexes taken from a crowded colony. The animals were immobilized dorsal side up and with their head fixed to a thin vertical Plexiglas plate placed on the underside of the neck with a bcc's wax and collophanium mixture. A watertight cup was build around the head for saline perfusion. A window of cuticle was opened between the compound eyes (sparing the antennae), and the air sacs on the anterior face of the brain were carefully removed. The base of the flagellum of one antenna was inserted in a short piece of polyethylene tubing and held along an axis parallel to that joining the two eyes. The distal $80 \%$ of the length of the flagellum was tree and could thus be used for direct airborne olfactory stimulation. The contralateral antennal nerve was cut as far as possible from the deutocerebrum. The esophagus was sectioned anterior to the brain, and the gut was removed through a dorsal section of the distal end of the abdomen, which was then ligatured to prevent leakage of saline. The dorsal protocerebral prominence surrounding the ocellar nerve on the side of the intact antenna was treated with (Sigma) type XIV protease, and very gently desheathed. The brain was supported by a wax-coated platform inserted from the anterior side between the two connectives, and superfused with physiological saline (in mu: $140 \mathrm{NaCl}, 5 \mathrm{KCl}, 5 \mathrm{CaCl}_{2}, 4 \mathrm{NaHCO}_{3}, 1 \mathrm{MgCl}_{2}$ 6.3 HEPES, $\mathrm{pH} 7.1$ ) at room temperature.

Electrophysiology. Intracellular recordings were made using glass microelectrodes pulled with a vertical (Kopf) or horizontal (Sutter) puller. The nature of the electrode solution and its concentration were of great importance. For that reason, conventional microelectrodes and intracellular recording techniques rather than blunt electrodes and wholecell patch-clamp techniques were used; $3 \mathbf{M} \mathrm{K}$-acetate, for example, invariably led to the death of the Kenyon interneurons upon penetration. Great improvements were brought about by using concentrations of $<0.5 \mathrm{M}$ or better, patch pipette internal solution [in mM: $155 \mathrm{~K}$-aspartate, $1.5 \mathrm{MgCl}_{2}, 1 \mathrm{CaCl}_{2}, 10 \mathrm{HEPES}, 10 \mathrm{EGTA}, 2 \mathrm{ATP} \mathrm{Mg}_{2}$ or ATP $\mathrm{Na}_{2}, 3$ D-glucose, $0.1 \mathrm{c} \Lambda \mathrm{MP}, \mathrm{pH} 7.0,350 \mathrm{mOsm}$; see Laurent et al. (1993)], giving electrode $D C$ resistances of $250-500 \mathrm{M} \Omega$ with the above internal solution. As shown in the Results, the input impedance of the interneurons (when recorded from the soma) was very large $(\sim 1 \mathrm{G} \Omega$ ), so only very small currents (10-50 pA) were generally needed to polarize them. The interneurons were therefore recorded in bridge mode with an Axoclamp 2A (Axon instruments) amplifier and data were recorded on DAT tape (DC to $5 \mathrm{kHz}$ ) for later analysis and display. Intracellular fills were carried out with iontophoresis of $3 \%$ cobalt hexamine in the standard way (Burrows and Siegler, 1984) and silver intensification (Bacon and Altman, 1977). Sections and whole-mounts were observed under a microscope and photographed, drawn with a camera lucida, or imaged with a Hamamatsu SIT camera mounted on a Nikon inverted microscope and image processing hardware (Hamamatsu). Local field potentials (LFP) were recorded with blunt electrodes (patch pipettes) filled with saline ( $\sim \mathrm{M} \Omega \mathrm{DC}$ resistance) connected to an intracellular amplifier. Local field potentials were low-pass filtered with a digital eight-pole Butterworth filter. For spectral and auto- or cross-correlation analysis, the physiological data were digitized off line at $2-8 \mathrm{kHz}$ with a National Instruments NBMIO16L AD/DA interface and analyzed with a Macintosh II microcomputer or a Sun Sparc2 workstation, using MATLAB. The data are based on intracellular recordings from $134 \mathrm{Ken}-$ yon cells and local field potential recordings from 39 animals.

Olfactory stimulation. The open ends of a set of four polyethylene tubes $(0.4 \mathrm{~mm}$ inner diameter) were placed $5 \mathrm{~cm}$ away from the antenna. The other end of three of these tubes were connected to three $1 \mathrm{ml}$ odorant-containing syringe bodies, which were connected to an air pressure injection system via a set of valves. Gentle pressure pulses (insufficient to bend the antenna visibly) were electronically controlled, and delivered at a variable rate. The fourth tube was used to supply a constant and gentle stream of air to the flagellum. The air and odorants were collected by a large funnel placed behind the animal and connected to a vacuum line. The syringe bodies were each used to deliver odorants or "blanks." The odorants were used pure or diluted $(0.1-0.001)$, and placed as aliquots of $1-50 \mu \mathrm{l}$ on a $1 \mathrm{~cm}^{2}$ piece of filter paper. We used crushed wheat or spinach leaves, and the following compounds: isoamylacetate, amyl-acetate, cis and trans citral, cineole (Aldrich); L-carvone, D-carvone, methyl-salicylate, cinnamon aldehyde (IFF Inc.); pine, cherry, strawberry, vanilla, musk, and citrus fragrances (Bell Flavors and Fragrances Inc.). Of these odorants, only "wheat" was familiar to the animals.

\section{Results}

Olfactory input pathway to the Kenyon cells

In locust, olfactory afferents from each antenna $(\sim 50,000)$ project to the ipsilateral antennal lobe, and synapse there onto local and projection neurons (Christensen and Hildebrand, 1987; Masson and Mustaparta, 1990). The antennal lobe in Schistocerca has an ellipsoid shape and, unlike insects such as moths and cockroaches, a microglomerular organization, as seen in cross section (Fig. 1A). There are an estimated 1000 glomeruli in each antennal lobe. Intracellular stains of projection interneurons allowed us to relate this gross morphology to that of the component neurons. The projection interneuron in Figure $2 A$ had its soma in a cluster on the anterior side of the lobe, a primary neurite that ran in a loop forming the outline of the central coarse neuropil, and 12 neurites radiating to the peripheral glomerular neuropil. Each of these neurites terminated in one or several tufts of fine branches (Fig. $2 A$ ), which each corresponded to a glomerulus. The average number of radial neurites per projection interneuron was $11 \pm 3$ ( $n=6$ interneurons). The projection ncurons sent axons through the antenno-glomerular tract (a.g.t.) toward the calyx of the mushroom body (Fig. $1 B$ ), where they gave sparse and varicose collateral branches over a wide area (Fig. $2 A$ ). This axon continued toward the lateral protocerebral neuropil, where its arborizations could not be traced further. Interneurons of this type ( $\sim 700$ a.g.t., Masson and Mustaparta, 1990) appear to constitute the only source of olfactory inputs to the Kenyon cells. The projections were, as described in previous studies, unilateral.

\section{Structure of the Kenyon cells}

Kenyon cells were stained by intracellular iontophoresis of cobalt hexamine from the soma. All neurons had a small $(6-8 \mu \mathrm{m})$ 

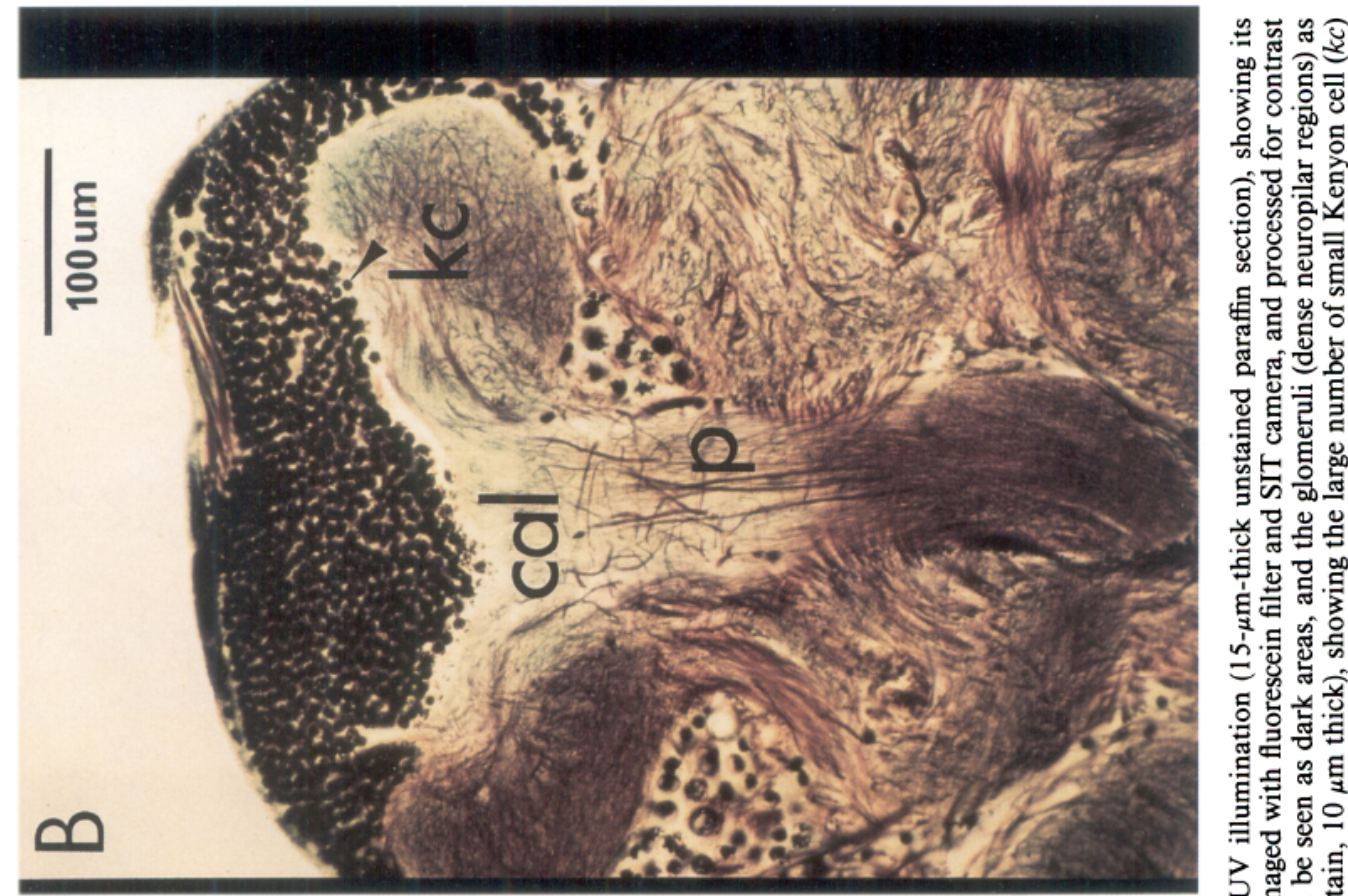

直语。

赵

。

용혀

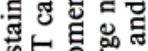

的的票

능웡

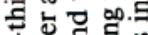

है त

它. 邹 운

$\triangle \mathbb{S}^{\circ}$

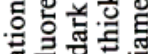

의

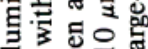

惯

ᄀ品菏

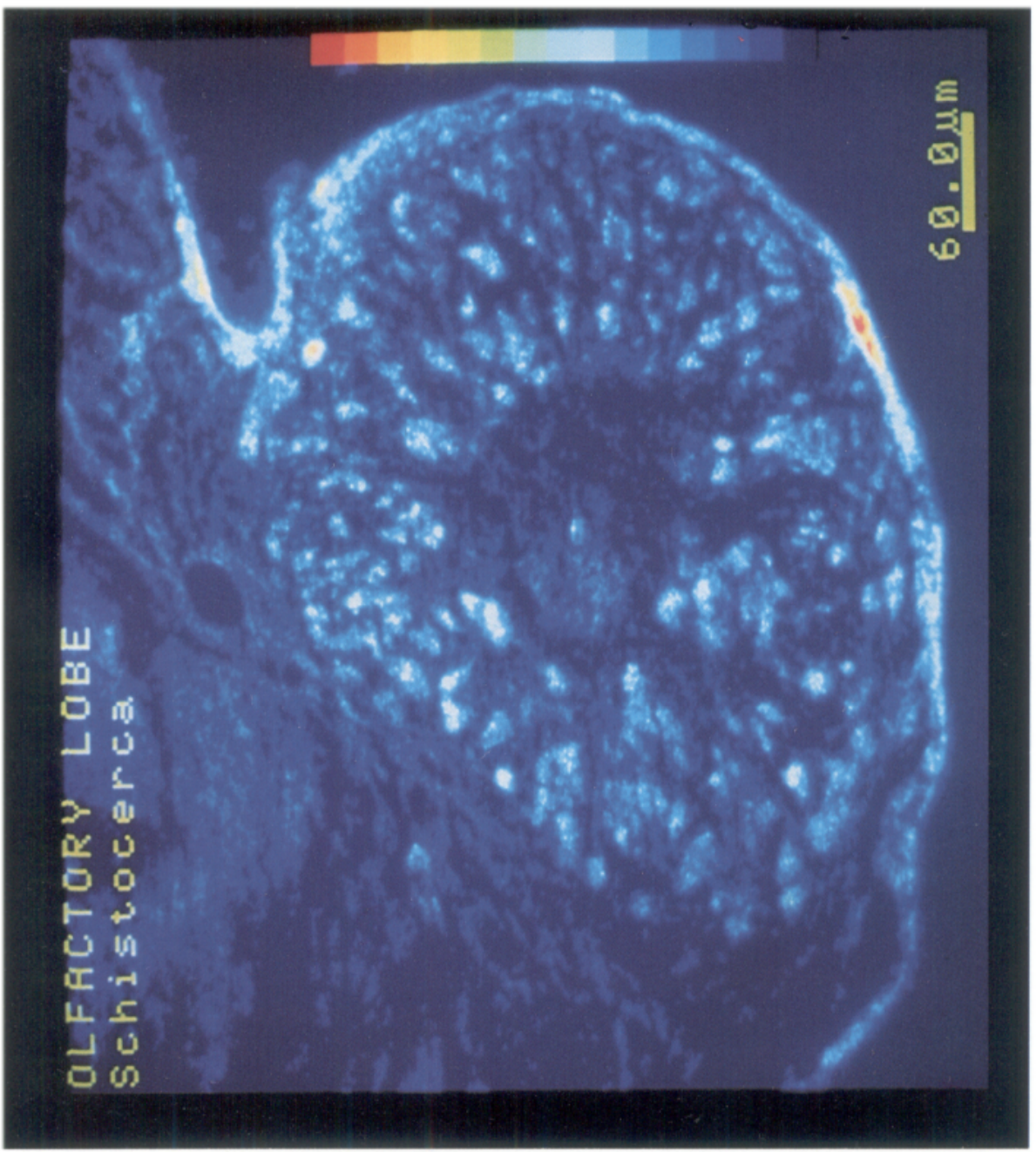

.

政的

o 80 응

腿

드월

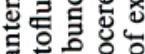
娄西 들 记 政 일 证 $\checkmark$ 등

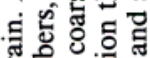
运 댕

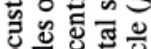
음 ه a 可 诃 음 픙 등 울둥 일 政 태용

융 융 त 을

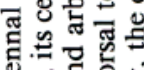
论皆 ष - 

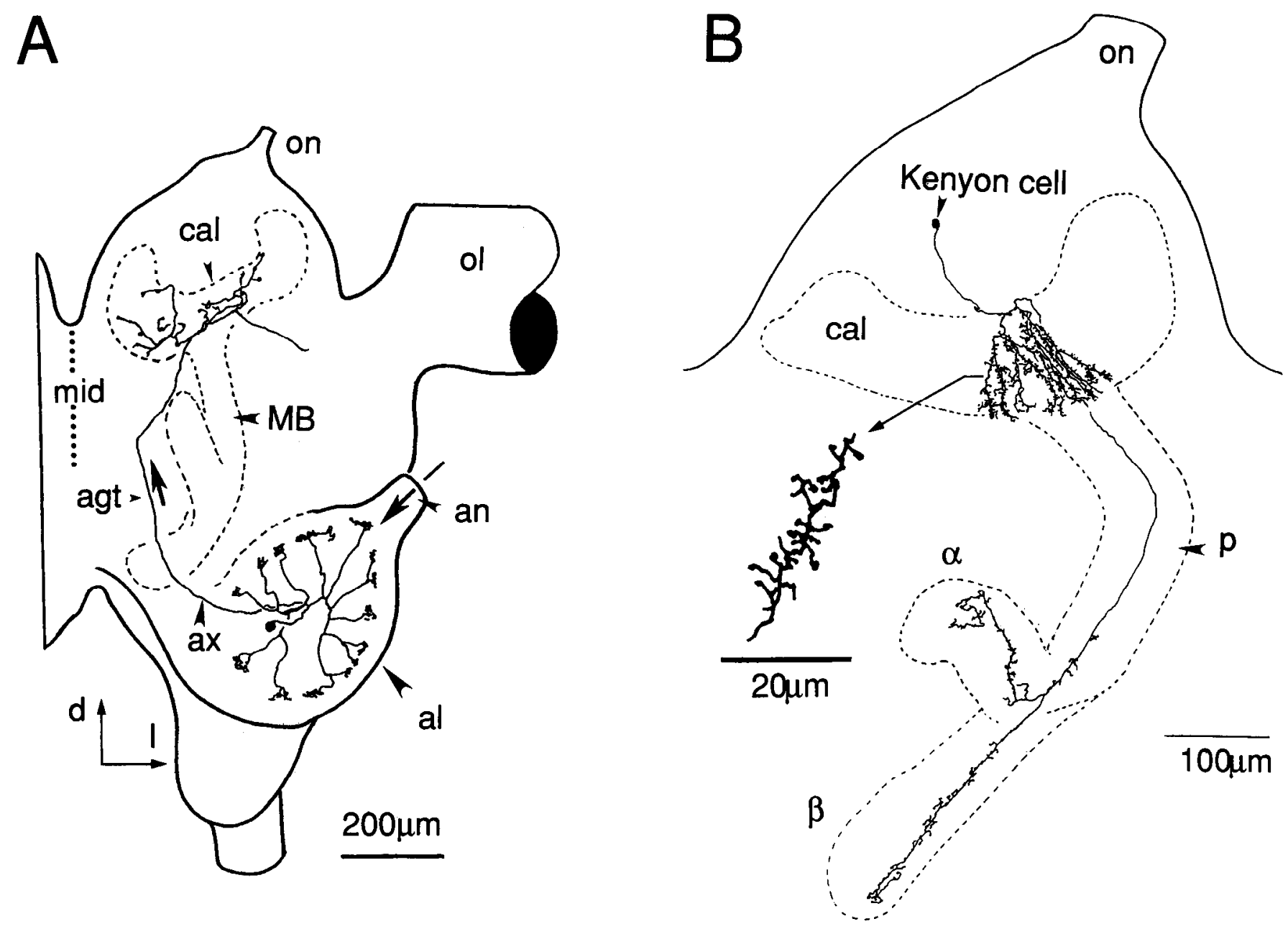

Figure 2. Projection of antennal lobe interneurons in antennal lobe and mushroom body and Kenyon cell morphology (camera lucida drawing of neurons stained by iontophoresis of cobalt hexamine). $A$, Arborizations of antennal lobe $(a l)$ projection neuron, showing tufts of short dendrites in individual glomeruli, radial secondary dendrites, soma, and axon (ax), exiting deutocerebrum via the antenno-glomerular tract (agt). The axon sends varicosc collatcrals in the calyx (cal) of the mushroom body $(M B)$, before projecting to the lateral protocerebral lobc. an, antennal nerve; mid, midline; $o l$, optic lobes; on, ocellar nerve. $B$, Kenyon cell in mushroom body. Note the small soma ( $7 \mu \mathrm{m}$ diameter), the primary neurite, the spiny secondary dendrites in the calyx ( $\mathrm{cal})$, the axon in the peduncle $(p)$, and the relatively unbranched axonal terminals in the $\alpha$ - and $\beta$-lobes. Neurons viewed from whole-mounts.

soma located dorsally (Fig. $1 B$ ) and a single primary neurite lcading to the dorsal edge of the calyx (Fig. 2B). There, this neurite gave rise to several secondary branches oriented radially, with spiny processes distributed every $2-5 \mu \mathrm{m}$ (Fig. $2 B$, inset). The shape of these spines varied from elongated and thin to short and stubby. The area over which the neurites of a Kenyon cell arborized varied, but was invariably smaller than that occupied by the calyceal collaterals of antennal lobe projection neurons. A single projection neuron, thus, probably diverges to many Kenyon cells in different regions of the calyx.

The axon of a Kenyon cell ran parallel to that of all the others, and could occasionally form very short (5-8 $\mu \mathrm{m})$ side branches, which were usually located in the distal half of the peduncle. The axon bifurcated and sent one branch in each of the two lobes (Fig. $2 B$ ). In one case, a Kenyon interneuron sent two branches in the $\alpha$ lobe in addition to that in the $\beta$-lobe. The axonal branches bore short side branches, generally distributed regularly along the length of the lobes (Fig. $2 B$ ). We did not stain Kenyon cells with arborizations in the accessory calyx.

\section{Population responses to odor stimuli}

LFP recordings were made from the Kenyon cell soma cluster, just dorsal to the calyx neuropil. When air alone was puffed onto one antenna, the population response in the ipsilateral mushroom body was a slow extracellular negativity, correlated with a sustained depolarization of individual Kenyon cells (Fig. $3 A$ ). Such a depolarization could, as shown here, lead to an action potential. When the air contained an odorant (e.g., cherry fragrance), the LFP in the ipsilateral mushroom body showed characteristic oscillations (Fig. $3 B$ ) that were generally maintained for the duration of the puff (up to $10 \mathrm{sec}$ ) and rapidly dissipated at the end of the stimulus. Power spectra of these oscillations peaked at $\sim 20 \mathrm{~Hz}$ (Fig. $3 B$, inset). Autocorrelation functions calculated for LFP oscillations evoked by all odorants tested (see list in Materials and Methods) revealed that their frequency was independent of the nature of the odorant (Fig. $4 A-C)$. A similar analysis of LFPs recorded during air puffs and in the absence of odor stimulus showed a small peak at \pm 50 

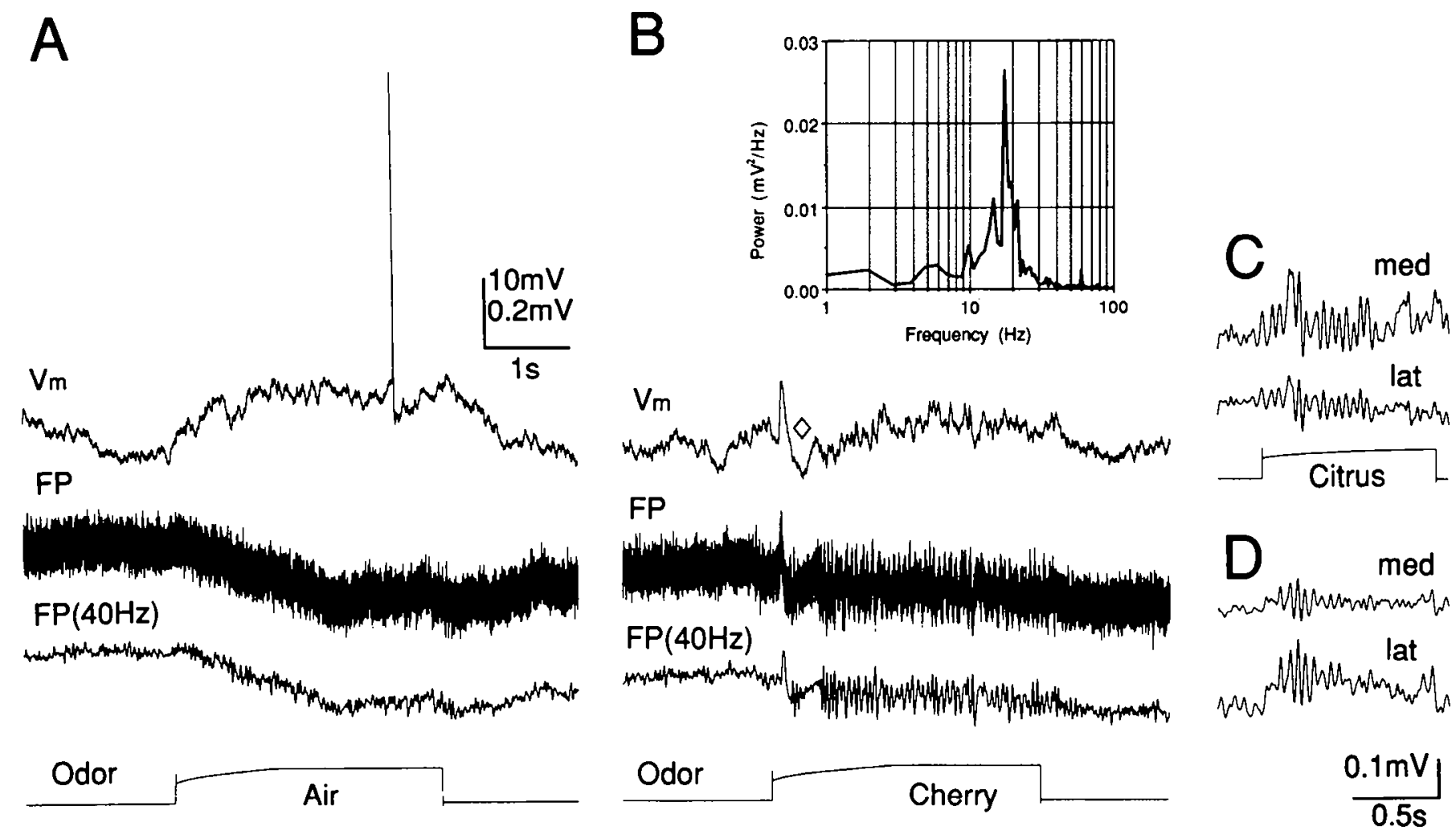

Figure 3. Odorant-induced oscillations in Kenyon cells of the mushroom body. A, A puff of air delivered to the antenna evoked a depolarization of a Kenyon cell $(\mathrm{Vm})$ and a slow negative deflection in the local field potential $(F P)$. Field potential trace (acquired at $3 \mathrm{kHz}$ ) low-pass filtered at $40 \mathrm{~Hz}[F P(40 \mathrm{~Hz})]$. Lower trace indicates duration of stimulus. $B$. If the puffed air contained an odorant (here cherry fragrance), the field potential showed large-amplitude oscillations that were briefly interrupted in the first $200 \mathrm{mscc}$ (diamond). Depolarization of Kenyon cell replaced by periodic and fast EPSPs. Note that oscillations cease shortly after the end of the odor delivery. Inset, Power spectrum of the LFP oscillations during odor stimulation, showing peak at $18 \mathrm{H} \%$. C. Paired LFP recording in two distant locations of the same mushroom body during citrus odor puff to ipsilateral antenna. med, medial; lat, lateral. $D$. Spontaneous oscillations occurring outside of periods of odor stimulation. Voltage calibrations in $A$ and $B: 10 \mathrm{mV}$, top trace; $0.2 \mathrm{mV}$, middle traces.

msec, but no peaks at multiple integers of this period, indicating a small intrinsic tendency of the mushroom body networks to oscillate at a frequency of $\sim 20 \mathrm{~Hz}$ (Fig. $4 D$ ).

During the period of sustained LFP oscillations, the membrane potential of the Kenyon cells remained near the resting level, and showed discrete periodic depolarizations, whose fine features will be described below. If the odor stimulus was new (as in Fig. 3B), the onset of the Kenyon cell response was sometimes a large EPSP, curtailed by a compound IPSP (diamond, Fig. $3 B$ ). This IPSP was always correlated with a correspondingly short decrease in the LFP oscillations amplitude, suggesting momentary desynchronization. Upon repeated presentation of the stimulus, however, the amplitude of the IPSP progressively decreased and eventually disappeared. Similarly, the short period of LFP desynchronization disappeared. Simultaneous LFP recordings from ipsilateral mushroom body sites separated by up to $300 \mu \mathrm{m}$ (Fig. $3 \mathrm{C}$ ) showed nearly identical LFPs, with no detectable phasc lag, suggesting synchrony of the entire population of Kenyon cells. Odor-evoked oscillations were never recorded in the mushroom body contralateral to the stimulated antenna. In all animals, short bouts of oscillations sometimes also occurred spontaneously (Fig. $3 D$ ), that is, outside of periods of odor presentation.

Ficld potential recordings from the core of the antennal lobes during odor puffs (five animals) showed no oscillations similar to those seen in the mushroom bodies (Fig. $5 A$ ). It is possible, therefore, that the LFP oscillations were generated in the mushroom bodics, or through feedback interactions with downstream neurons. Alternatively, it is also possible that the glomerular architecture of the antennal lobes precludes recording the coordinated activity of many neurons with field potential electrodes.

Some odorants (such as strawberry wheat leaves, and vanilla) failed to evoke strong oscillations upon initial presentation (Fig. $5 B$ ), even when delivered at high concentrations. If the odorant was presented several times successively at $1.5-10$ sec interval, however, the second or following presentation evoked field oscillations (Fig. $5 B$ ), suggesting rapid plastic changes. Short-term plasticity was not investigated further in this study.

\section{Responses of Kenyon cells to odor and antennal stimuli}

Intracellular recordings were made from the somata of $134 \mathrm{Ken}$ yon cells. Stable recordings could be obtained for up to $45 \mathrm{~min}$. Their resting potential was between -70 and $-60 \mathrm{mV}$. Their firing rate was generally low at rest (mean $\sim 2 \mathrm{~Hz}, 56$ interneurons). Their DC input resistance at the soma (measured from the slope of the $I-V$ curve at $-90 \mathrm{mV})$ was $0.95 \pm 0.18 \mathrm{G} \Omega(n$ $=8$ interneurons). All Kenyon cells showed spike accommodation during prolonged depolarizing current pulses. To ascertain the nature of the composite synaptic drive to Kenyon cells during the odor-induced oscillations, DC current was applied to individual neurons during odor presentation (Fig. 6). Ex- 
A

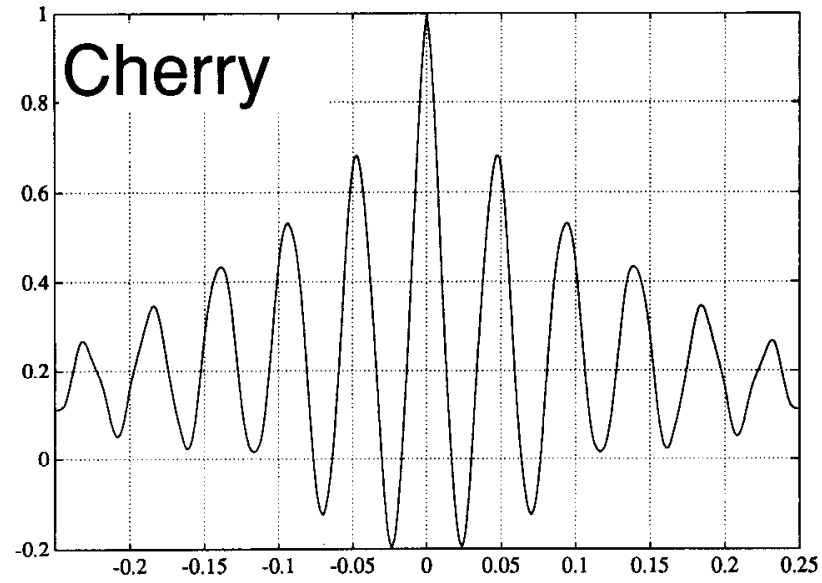

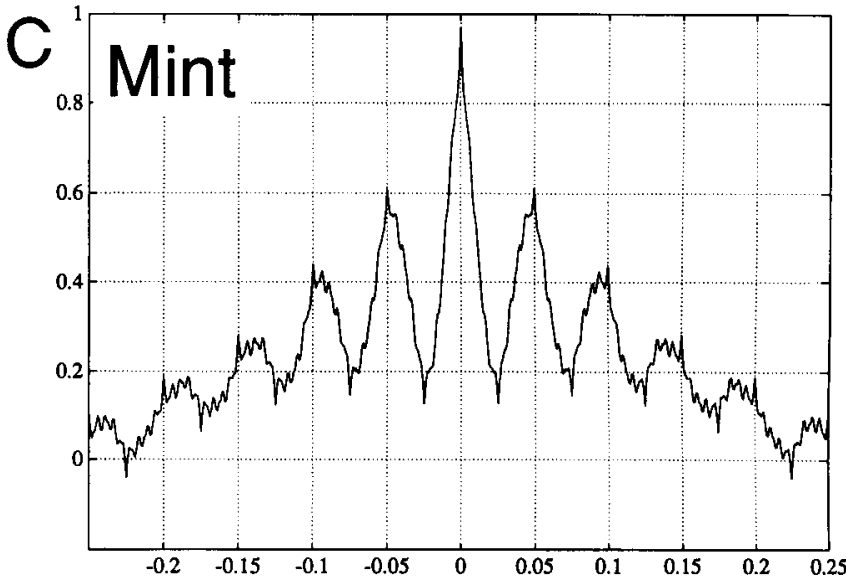
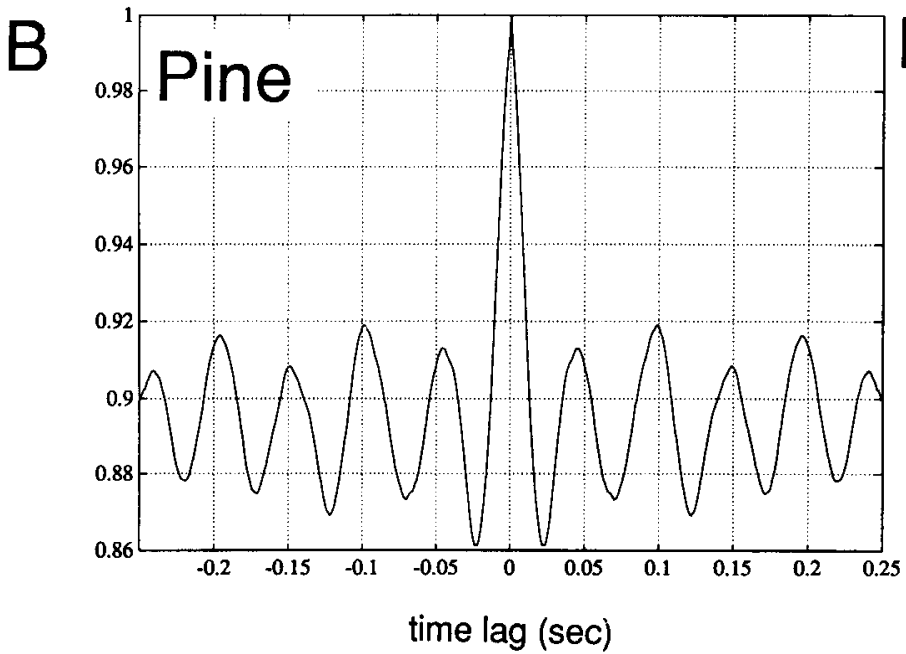

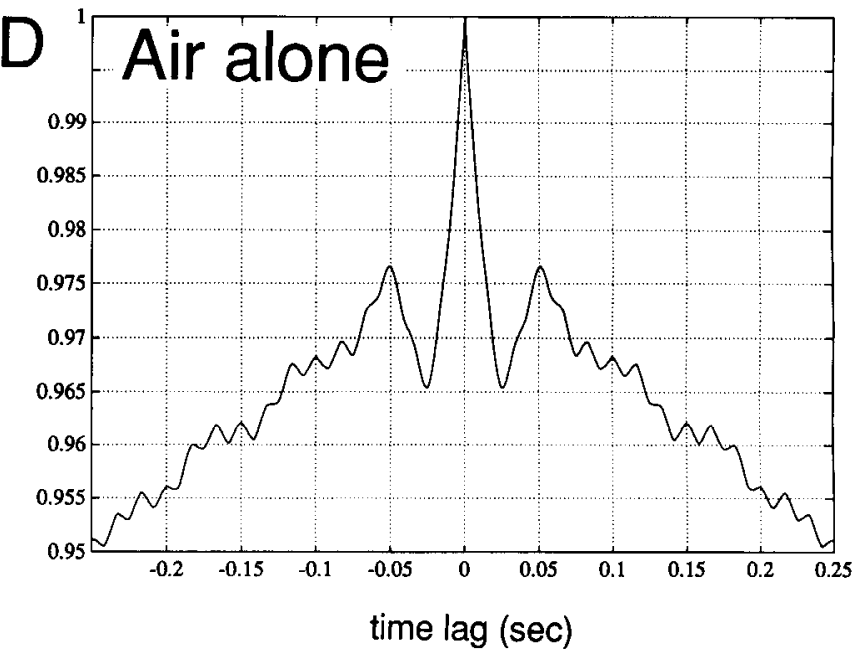

Figure 4. Autocorrelation functions calculated for LFP oscillations evoked by three different odors $(A-C)$, and air alone $(D)$. Ordinate normalized to peak. The different noise levels are due to the presence or absence of prefiltering of LFP records, and to the different lengths of record analyzed. The reduced modulation range in $B(15 \%)$ is due to DC offset.

amples are shown here of cells that did not respond strongly to the odor pulses, so that the underlying synaptic features of the responses can be clearly seen. Three main features (detailed below) were noticed: (1) the response of a Kenyon cell was always shaped by a combination of inhibitory (possibly via a reduction of a tonic excitatory background) and rhythmic excitatory inputs; (2) the membrane potential oscillations were phase-locked to the LFP; (3) the Kenyon cell dendrites had voltage-dependent currents capable of boosting the periodic depolarizing potentials.

Figure 6 shows the response of a Kenyon cell to a pulse of cherry odor. At resting potential, the response was characterized by a train of fast membrane potential oscillations and an interruption of the low tonic spiking activity. This inhibition of firing is better seen in Figure 7, where several traces are superimposed, and used to produce an average spike frequency histogram. At hyperpolarized potentials, the response consisted of the same oscillations superimposed on a small sustained depolarization, possibly caused by the reversal of an inhibitory component (Fig. 6). At depolarized potentials, the response consisted of an interruption of the tonic firing (induced by DC current injection), and an amplification of the periodic depolarizing potentials. One of these potentials reached threshold, and the following cycle was rendered invisible by the large spike afterpotential. Depolarizing a Kenyon cell in the absence of LFP oscillation never evoked such regular oscillations of membrane potential. These were therefore at least partly synaptically driven. This composite synaptic drive during the LFP oscillations is further illustrated in Figure 8, showing records from a different Kenyon cell. That the response to an odor contained an inhibitory component can be seen from the large hyperpolarization following the initial EPSP (Fig. 8A) and from the inhibition of current-induced firing during the LFP oscillations (Fig. $8 B$ ). Spiking resumed some time after the LFP oscillations disappeared.

Pathway tracing in other studies (e.g., Schürmann, 1974) suggested that Kenyon cells receive direct synaptic inputs on their spines from the antennal lobe projection interneurons (see Fig. 2 ), and that this pathway is the only one connecting the antennal afferents to the calyx of the mushroom bodies. Because the antennal projection interneurons respond to olfactory and/or mechanosensory inputs from the antenna (Burrows et al., 1982; Christensen and Hildebrand, 1987), we stimulated the antennal nerve with extraccllular clectrodes and thereby evoked polysynaptic responses in the Kenyon interneurons. The PSPs de- 


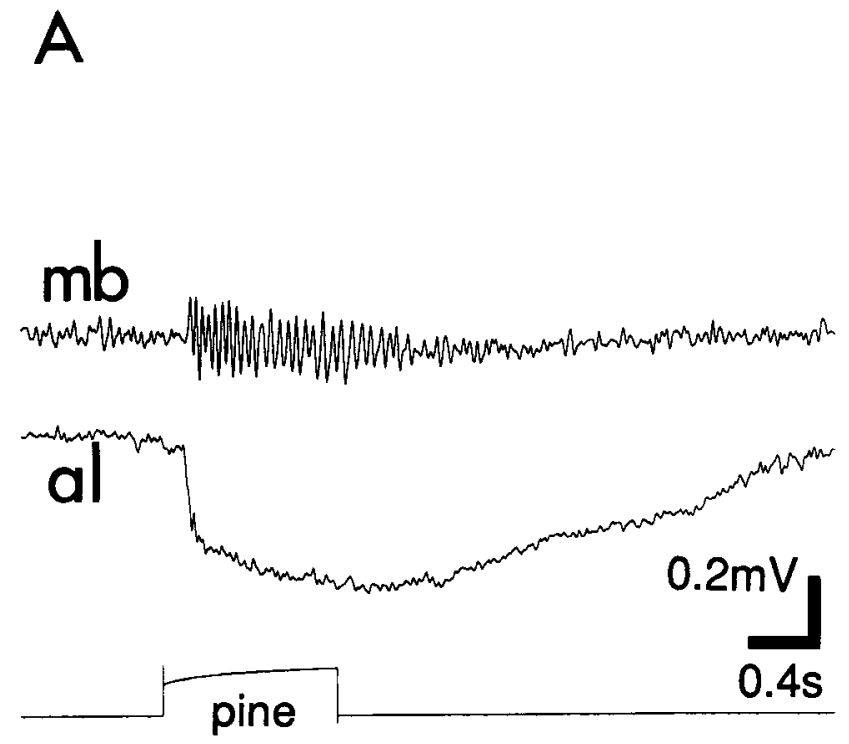

B

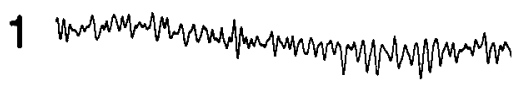

2 wartumpurmos)

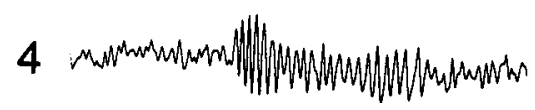

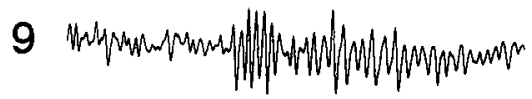

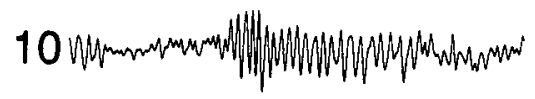

strawb.

Figure 5. Odorant-evoked LFP oscillations can be seen in the mushroom body $(\mathrm{mb})$ but not in the antennal lobe $(a l)(A)$. Both LFP records lowpassed filtered at $40 \mathrm{~Hz}$ (see Materials and Methods). $B$, Sample of LFP responses in the mushroom body upon repeated presentation of strawberry odor. The first presentation failed to evoke oscillations, but the following ones did. Interpulse interval was 5 sec. Responses $1,2,4,9$, and 10 are shown. Calibration is as in $A$, and LFP traces low-pass filtered at $40 \mathrm{~Hz}$.
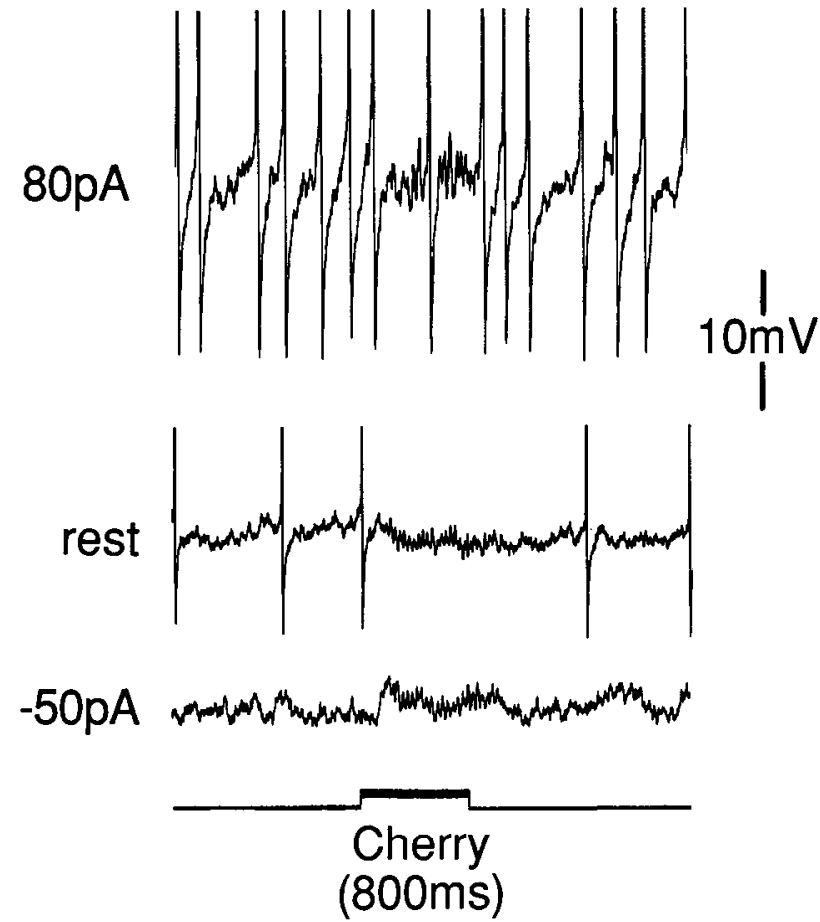

Figure 6. Nature of the oscillatory synaptic drive to Kenyon cells: intracellular recording from Kenyon cell, showing composite response during odor-evoked LFP oscillations. Resting potential: $-65 \mathrm{mV}$. Top, $80 \mathrm{pA}$ holding DC current. The Kenyon cell spikes (action potentials clipped). The action potentials are interrupted during odor pulse. Membrane potential oscillations are seen. One reaches threshold. Middle, Resting potential. Low firing rate. Odor pulse evokes membrane potential oscillations and interrupts tonic firing. Bottom, $-50 \mathrm{pA}$ holding current. Odor pulse evokes oscillations superimposed on reversed inhibitory synaptic component. scribed below were therefore evoked directly by the antennal projection interneurons, although other neurons might have been interposed between them and the afferents which we stimulated electrically. Stimulation of the antennal nerve suggested that Kenyon cells receive only excitatory input from the antennal lobe projection neurons (Fig. 9Ai,Bi). These potentials were chemical EPSPs for they could summate, lead to action potentials and were enhanced by injection of hyperpolarizing current. These EPSPs occurred after a delay of 15-25 msec. and could be amplified by intrinsic voltage-dependent properties of the Kenyon cell dendrites, seen as sharp depolarizations riding on the "passive" EPSPs (arrowhead, Fig. 9Bi). The active depolarizing components could be evoked either by holding the Ken-
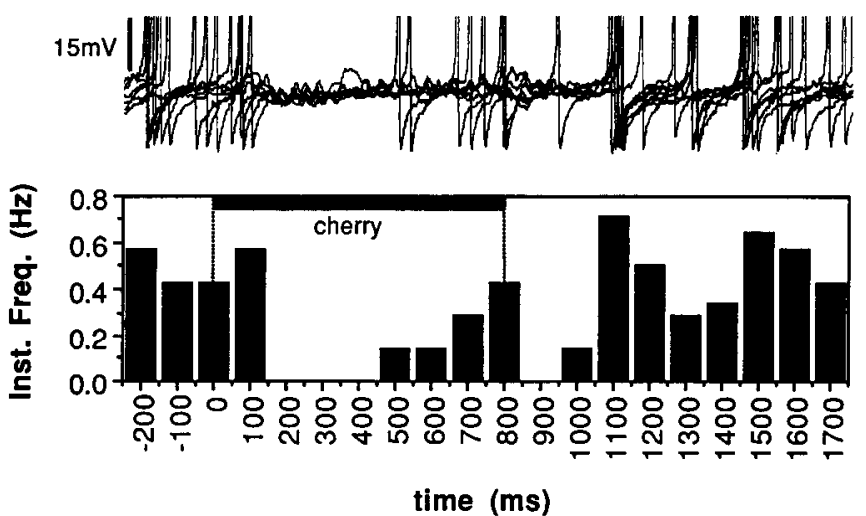

Figure 7. Superimposed traces from Kenyon cell in Figure 6, showing the temporary inhibition of firing following presentation of "cherry" odor at resting potential. Time base is as in histogram below. Action potentials were truncated. The average instantaneous spike frequency histogram below the traces was constructed from 14 odor presentations, aligned at onset of odor pulse. Note the recurrent EPSPs during the odor pulse, and their occasionally leading to an action potential. 

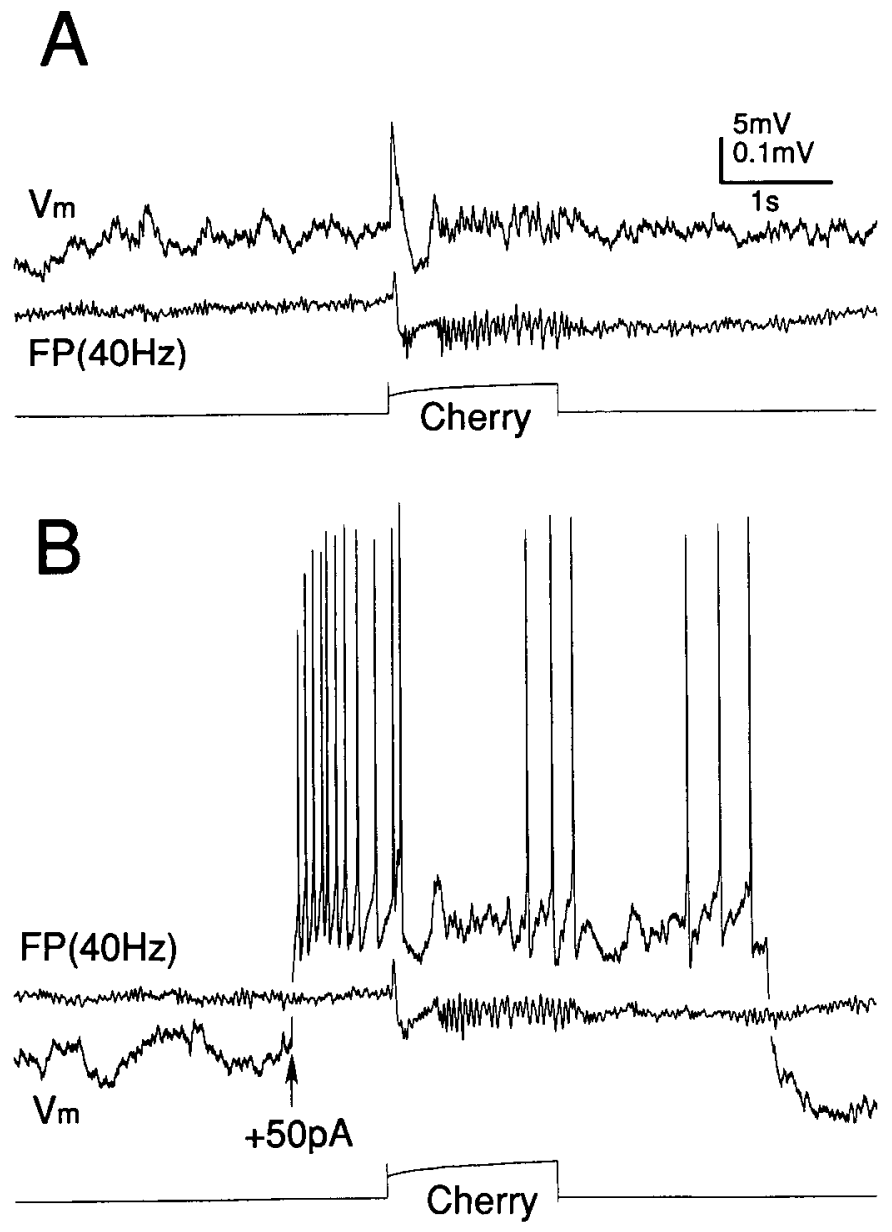

Figure 8. Compound synaptic activity during odor-pulse. $A$, A new Kenyon cell $(\mathrm{Vm})$, illustrating the initial EPSP, the following pronounced hyperpolarization, and the rhythmic EPSPs during the LFP oscillations. $B$, Same interneuron and response to odor-pulse during DC current pulse. The current pulse leads to firing that is interrupted by the odor presentation. Some of the rhythmic EPSPs are now suprathreshold. Spiking resumes some time after the LFP oscillations dissipate. LFP low-pass filtered at $40 \mathrm{~Hz}$. Calibration: $5 \mathrm{mV}, V m$ traces; $0.1 \mathrm{mV}, L F P$ traces.

yon cell depolarized with constant current, or, like here, by increasing the strength of the antennal nerve stimulus. Conversely, the active components could be suppressed by holding the Kenyon cell hyperpolarized. The fast repolarization following the active component of these EPSPs was faster than that of the passive EPSPs, suggesting also the existence of active repolarizing currents (Fig. 9B).

Because synaptic potentials evoked by antennal lobe projection interneurons could be contaminated by voltage-dependent events, the possibly graded nature of the antennal lobe input could only be studied if Kenyon cells were held hyperpolarized to $\sim-100 \mathrm{mV}$, that is, at potentials where the active conductances would not be recruited. In these conditions, a gradual increase in the antennal stimulating current led to a graded increase in the EPSP amplitude. At least 8-10 discrete EPSP amplitude levels could he distinguished with any Kenyon cell, suggesting that each Kenyon cell receives excitatory inputs from at least as many antennal lobe projection interneurons.

During odor-evoked responses, the Kenyon cell membrane potential and LFP oscillations were phase-locked. The peak of

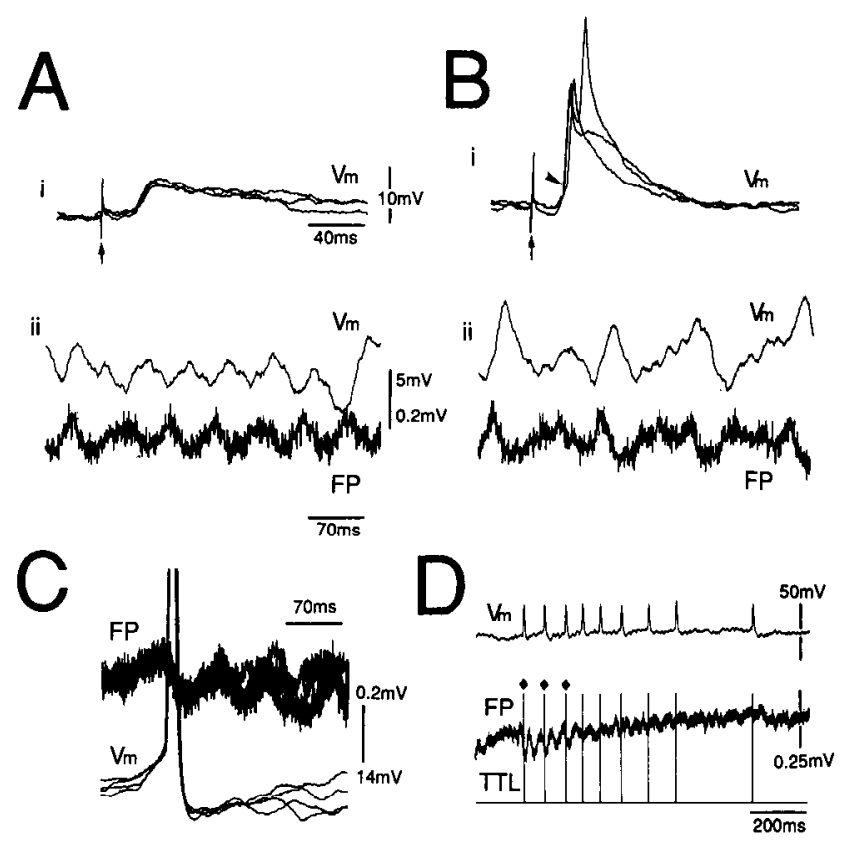

Figure 9 Synaptic and voltage-dependent properties of Kenyon cells. $A$ and $B$, Response of Kenyon cell to electrical stimulation (arrow) of ipsilateral antennal nerve $(i)$, and to odor delivery $(i i)$. $A i$, EPSPs evoked by low electrical stimulus intensity. $B i$, EPSPs with superimposed active component (arrowhead) evoked by increasing antennal nerve stimulus amplitude. Aii, Simultaneous intracellular recording from Kenyon cell $(V m)$ and LFP $(F P)$ showing phase-locking of the two signals. Bii, Same as $\mathrm{Aii}$, showing correlation between amplitudes of compound synaptic potentials in Kenyon cell (possibly amplified by voltage-dependent currents) and that of LFP oscillations. $C$, Four superimposed traces triggered from rising phase of Kenyon cell spikes, showing phase-locking between action potentials $(V m)$ and population response $(F P)$. D , Different Kenyon cell during response to pine fragrance pulse, showing correlation between LFP amplitude and relative timing of the spike (TTL pulses triggered from rising phase of spikes in $V^{\prime} m$ trace). The solid diamonds indicate three cycles where LFP amplitude is large, and timing of action potential corresponds precisely to descending phase of LFP oscillation (little or no jitter). Other spikes often occur at different phases of the cycle, and the LFP amplitude is smaller.

compound EPSPs occurred during the negative phase of the LFP oscillation (Fig. 9Aii), and the amplitude of the recurring depolarization of an individual Kenyon cell was sometimes correlated, on a cycle to cycle basis, with that of the corresponding LFP oscillation recorded nearby (Fig. 9Bii). If a phasic depolarization of a Kenyon cell, amplified by the intrinsic voltagedependent dendritic properties, exceeded threshold, it led to an action potential, whose timing was then phase-locked to the LFP oscillation (Fig. 9C), indicating synchrony with many other neurons in the population. No Kenyon cell was found to fire on consecutive cycles of an oscillatory bout. The Kenyon cell in Figure $9 D$, for example, fired at the most on alternate cycles. In the cases where an action potential was fired, the amplitude of each LFP oscillation was correlated with the relative timing of the Kenyon cell action potential. On cycles where the LFP amplitude was large, the action potential coincided precisely with the descending phase of the LFP oscillation (diamonds, Fig. $9 D$ ). In other words, the timing of the action potential showed little or no jitter. On cycles where the LFP amplitude was small, by contrast, the spikes occurred at variable phase angles. 


\section{Discussion}

The tentative olfactory circuits within which the Kenyon cells of the insect mushroom body are embedded are represented schematically in Figure 10. This summary diagram is constructed entirely from previously published anatomical studies (Kenyon, 1896; Trujillo-Cenóz and Melamed, 1962; Pearson, 1971; Schürmann, 1974; Weiss, 1981; Burrows et al., 1982; Mobbs, 1982; Schildberger, 1983, 1984; Gronenberg, 1987; Homberg et al., 1988; Rybak and Menzel, 1993). These data suggest distributed feedforward inputs from the ipsilateral antennal lobe projection neurons and the existence of feedback loops between the Kenyon cells axons in the $\alpha$ - and $\beta$-lobes and their spiny dendrites in the calyx via feedback neurons. We report here the first in vivo intracellular and LFP recordings from Kenyon cells during processing of olfactory signals. These results establish simple modifications of conventional techniques, making the electrophysiological analysis of olfactory processing and synaptic plasticity in this system possible. They reveal that Kenyon cells are complex integrative elements, and that olfactory stimuli evoke, like in the olfactory systems of vertebrates (Adrian, 1942) and the mollusk Limax (Gelperin and Tank, 1991; Delaney et al., 1994), seemingly correlated activity of large ensembles of neurons. Surprisingly, such oscillations were not reported in a current source-density analysis of information processing in the mushroom bodies of the honeybee (Kaulen et al., 1984). It is possible that the oscillations (if present) were missed because this analysis relied on averaged evoked potentials. Our data suggest that oscillations and phase-locking may be basic computational requirements for olfactory processing and learning, which were arrived at several times and independently throughout evolution.

\section{LFP oscillations: possible origins and mechanisms}

Extracellular recordings from various loci within the cluster of Kenyon cell somata, just dorsal to the calyx, revealed oscillatory LFPs in response to odor presentation. These oscillations were restricted to the mushroom body ipsilateral to the stimulated antenna, and appeared to be spatially coherent; that is, they did not seem to form a traveling wave from one part of the calyx to another. (A note of caution should be introduced, for this could only be assessed by paired "point sampling.") During the oscillations, the membrane potential of individual Kenyon cells fluctuated in phase with the extracellular potential, without necessarily exceeding spike threshold. When a Kenyon cell produced an action potential, it produced only one per cycle, and generally did not produce ones on successive cycles. (Damaged Kenyon cells often produced doublets during a cycle, but this was only rarely seen with healthy cells.) Depolarizing current pulses alone failed to evoke Kenyon cell membrane potential oscillations, suggesting that the oscillations were primarily due to emergent properties of the networks.

It is still too early to speculate on the likely intrinsic and synaptic mechanisms underlying such oscillatory behavior. The intrinsic properties of Kenyon cells are as yet unknown, and the circuits that they form are only sparsely described. The present results, however, lead to several questions. (1) Are the Kenyon cells "tuned" to oscillate at the observed frequencies? Such intrinsic electrical behavior would, on its own, be insufficient to account for the intercellular coupling and the apparent synchronized activity, but might favor one (or a window of) oscillating frequency(ies). The present results suggest the existence

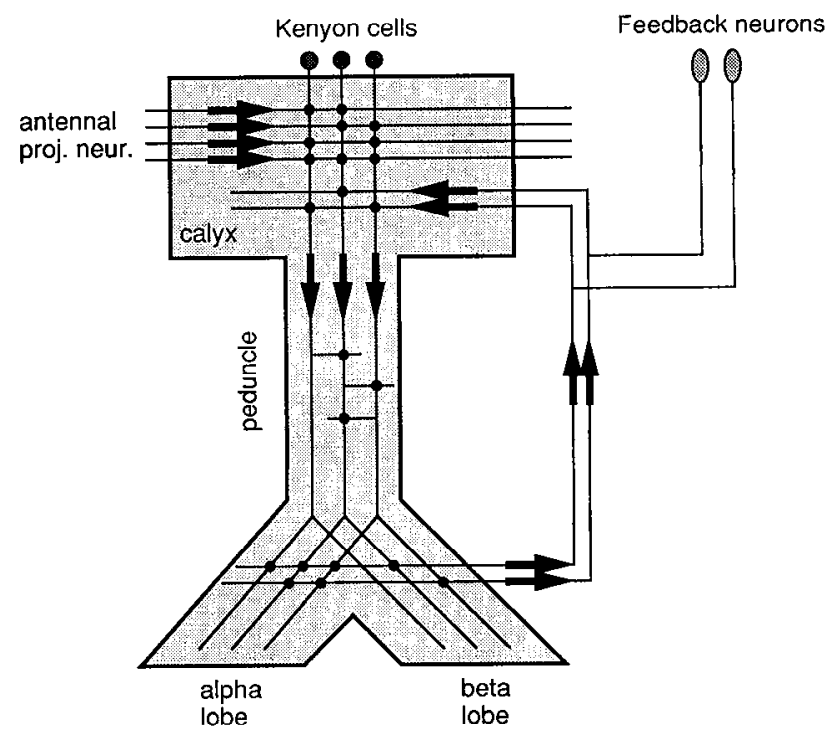

Figure 10. Schematic diagram of the putative anatomical circuits formed by Kenyon cells in the mushroom body (anatomical data collected from published work in honeybees, crickets, Manduca, and locusts). The Kenyon cells receive distributed olfactory inputs from the antennal lobe projection interneurons. The synapses are probably made onto the spines of the Kenyon cells in the calyx (Schürmann, 1974, 1987), and are excitatory (present results). The Kenyon cells may form lateral chemical synapses with neighboring axons in the peduncle (Schürmann, 1974) and contact the dendritic endings of "feedback" interneurons in the lobes (Schildberger, 1983, 1984; Gronenberg, 1987; Homberg et al., 1987; Rybak and Menzel, 1993). The putative dynamic polarization of these "feedback" neurons is only inferred from morphological data. These "feedback" interneurons may receive their inputs primarily from the $\alpha$-lobe, project back into the calyx, and contact the Kenyon cells there. Some of these "feedback" interneurons are in a cluster of GABAimmunoreactive cells (Bicker et al., 1985; Homberg et al., 1987) and are therefore probably inhibitory. In no species have the Kenyon cells been found to be GABA immunoreactive (e.g., Bicker et al., 1985; Homberg et al., 1987). They are therefore probably excitatory. The arrows represent the inferred direction of information flow. The small solid circles represent synaptic contacts.

of voltage-dependent nonlinearities in the Kenyon cell ncurites. The activation and inactivation properties of these currents and their ionic selectivity need to be described (possibly in vitro) before this question can be answered. (2) Do the Kenyon cells express a hyperpolarization-activated cation current $\left(I_{h} ; \mathrm{Katz}\right.$, 1949)? Such currents have been described in many rhythmically active cell types and networks (e.g., McCormick and Pape, 1990), and have recently been proposed, via numerical simulations, as a mechanism to produce population rhythms from simple networks of units that are not capable of oscillating on their own (Kopell and LeMasson, 1993). The apparent advantage of this cellular mechanism is that it allows for a relatively stable oscillatory frequency over a wide range of LFP amplitudes. Consequently, the frequency of the population is somewhat independent of the fraction of active neurons in the network, and therefore, small microcircuits within the population could be functionally "isolated" for independent processing (Kopell and LeMasson, 1993). Large hyperpolarizing current pulses delivered to the soma of Kenyon cells failed to reveal the typical voltage "sag" normally caused by the activation of $I_{h}$, but a more rigorous biophysical characterization remains necessary. (3) Do the Kenyon cells activate inhibitory and excitatory feedback neurons? As shown in the results, $20 \mathrm{~Hz}$ oscillations were 
not observed in the antennal lobes. The oscillations may therefore possibly be produced by the networks formed between Kenyon cells and "extrinsic" mushroom body neurons, many of which seem to originate in the $\alpha$-lobe (e.g., Schildberger, 1981, 1984; Gronenberg, 1987; Rybak and Menzel, 1993; see Fig. 10). Our results also suggest that the oscillatory response of individual Kenyon cells contains an inhibitory component. It is improbable that this inhibition originates in the antennal lobes, for only EPSPs could be evoked in Kenyon cells by stimulation of the antennal lobe projection neurons. This is consistent with immunocytochemical studies suggesting that the antennal lobe projection neurons are cholinergic (Lutz and Tyrer, 1987). It seems, therefore, that one component of the feedback circuits should be inhibitory. Possible feedback inhibitory neurons are the cluster of protocerebral $\mathrm{G} \Lambda \mathrm{B} \Lambda$-immunoreactive neurons with arborizations in the lobes and the calyx (Bicker et al., 1985; Homberg et al., 1987). Their activity during olfactory processing, however, has yet to be studied. It should be emphasized that, although population oscillations where not seen in LFP recordings from the antennal lobes, oscillations might still be present in individual antennal lobe neurons but not detectable as a population response. (4) Are Kenyon cells functionally coupled to each other? Lateral excitatory coupling between the Kenyon cells might indeed participate locally in the synchronization of their activity. Kenyon cells, however, lack axon collaterals that could feed back directly onto the calyceal dendrites of other Kenyon cells. Alternatively, Kenyon cells could make dendrodendritic synapses among each other in the calyx. It does not seem, however, that their spiny dendrites contain presynaptic specializations (Schürmann, 1974, 1987). Lateral connections between Kenyon cells could finally take place in the peduncle or the lobes. Schürmann (1974) did indeed describe pre- and postsynaptic specializations in the Kenyon cell axons at the level of the peduncle (Fig. 10). Such anatomical contacts are intriguing, however, for their location falls neither in the "classical" dendritic territory (i.e., the calyx), nor close to the axonal terminals in the lobes. Hence, the possible function and mode of action of such lateral contacts appear unclear to us at this time.

\section{Oscillations and olfactory coding}

The interest in collective oscillations in neuronal networks has been revived recently by theoretical and experimental work (primarily with the visual cortex of mammals) on feature linking (or binding), pattern segmentation, and visual attention (von der Malsburg and Schneider, 1986; Eckhorn et al., 1988; Gray and Singer, 1989; Crick and Koch, 1990; Sompolinsky et al., 1990, Gerstner et al., 1993). Oscillations in the brain, however, had been described long before in the olfactory bulb and piriform cortex of vertebrates (Adrian, 1942; Freeman, 1975). The frequency of these oscillations ranges from $40 \mathrm{~Hz}$ in man and large mammals, to $50-60 \mathrm{~Hz}$ in small mammals such as rats, hedgehogs, and rabbits (Wooley and Timiras, 1965; Ketchum and Haberly, 1990). The oscillations are generally evoked during inspiration or sniffing and are amplified by odor delivery. Their frequency, however, is, as was seen here, independent of the nature of the odorant. Coding in the piriform cortex might, according to Freeman $(1975,1979)$, depend on the spatial patterns of the odor-induced oscillations amplitudes. The oscillations would, in this scheme, form a spatial template for expected odors. Our observation in Schistocerca that certain odorants evoked oscillations only after prolonged or repeated presenta- tion is interesting in this context. This interpretation, however, does not always fit our results, for other odors (such as cherry and mint) evoked large-amplitude oscillations even upon the first presentation, despite the fact that the animals had never been exposed to them previously.

Alternatively, the oscillations in piriform cortex might form the basis for Hebbian reinforcement of synapses during olfactory learning (Haberly, 1985; Haberly and Bower, 1989). A characteristic of piriform cortex architecture is the distributed nature of its afferent projections, the large number of intrinsic neurons, and the large number and horizontal spread of the association fiber (positive feedback) system (Haberly, 1985). This architecture is reminiscent of that of formal content-addressable memory (CAM) networks (Anderson, 1972; Kohonen, 1977; Hopfield, 1982), whose advantage is to allow (under certain conditions) the complete recall of a memory from fragmentary or corrupted inputs. In this context, it was proposed that the oscillations (though not required for CAM networks) might allow the repetitive pairing of afferent input and recurrent signals from the association fibers, thus participating in memory formation by synaptic enhancement. The architecture of the mushroom bodies partially fits that of CAM systems (Fig. 10): relatively few afferent fibers (700 projection neurons from the antennal lobe) diverge to a large number of processing elements (about 50,000 in Schistocerca). Feedback pathways from and to the Kenyon cells certainly exist, but whether they are distributed or specific is so far unknown. Finally, although the role of the mushroom bodies in learning seems undisputed, nobody appears yet to know whether the sites for plasticity are the synapses between antennal lobe neurons and Kenyon cells, those between Kenyon cells and efferent neurons, both, or yet other synapses. The apparent patterns of distribution of the dunce, rutabaga and DCO proteins in the Kenyon cells of Drosophila suggest that both the input (calyceal) and output (peduncle and lobes) synaptic sites of Kenyon cells could be the sites of cAMPdependent modifications (Davis, 1993).

More recently, electrophysiological and imaging experiments in the mollusk Limax showed oscillatory activity of a slightly different type (Gelperin and Tank, 1990; Delaney et al., 1994). In the isolated procerebral lobe of Limax, slow $(0.5-1 \mathrm{~Hz})$ oscillatory activity occurs in the absence of odorant stimuli. At rest, the oscillations take the form of a propagating wave along the long axis of the lobe. When an odorant (such as potato or garlic) is presented, however, the phase gradient across the lobe collapses, leading to synchronous oscillations of the entire lobe. The propagating wave recovers within several seconds after the end of the odorant stimulus. Delaney et al. (1994) propose that "the synchronous state might represent a change in attentiveness of the animal to its olfactory environment." Our results do not, at present, suggest the existence of such waves along a given axis of the mushroom body.

In conclusion, our results demonstrate the existence of odorant-evoked $20 \mathrm{~Hz}$ oscillations in the mushroom bodies of an insect, and establish several phenomenological parallels with information processing in the olfactory systems of mammals and the terrestrial mollusk Limax, suggestive of possibly similar computational schemes. These results may also form a link between the numerous behavioral studies of olfactory learning in social insects (cf. Menzel et al., 1974) and the powerful molecular approaches started with Drosophila mushroom bodies (Dudai et al., 1976). 


\section{References}

Adrian ED (1942) Olfactory reactions in the brain of the hedgehog. J Physiol (Lond) 100:459-473.

Anderson JA (1972) A simple network generating an interactive memory. Math Biosci 14:197-220.

Arnold G, Masson C, Budharugsa S (1985) Comparative study of the antennal lobes and their afferent pathway in the worker bee and the drone (Apis mellifera). Cell Tissue Res 242:593-605.

Bacon JP, Altman JS (1977) A silver intensification method for cobaltfilled neurons in whole mount preparation. Brain Res 138:359-363.

Balling A, Technau GM, Heisenberg M (1987) Are the structural changes in adult Drosophila mushroom bodies memory traces? Studies on biochemical learning mutants. J Neurogenet 4:65-73.

Bicker G, Schäfer S, Kingan TG (1985) Mushroom body feedback interneurons in the honeybee show GABA-like immunoreactivity. Brain Res 360:394-397.

Boeckh J, Ernst KD (1987) Contribution of single unit analysis in insects to an understanding of olfactory function. J Comp Physiol [A] 161:549-565.

Burrows M, Siegler MVS (1984) The morphological diversity and receptive fields of spiking local interneurones in the locust metathoracic ganglion. J Comp Neurol 224:483-508.

Burrows M, Bocckh J, Esslen J (1982) Physiological and morphological properties of interneurons in the deutocerebrum of male cockroaches which respond to female pheromone. J Comp Physiol [A] 145:447457.

Christensen TA, Hildebrand JG (1987) Functions, organization and physiology of the olfactory pathways in the lepidopteran brain. In: Arthropod brain. Its evolution, development, structure and functions (Gupta AP, ed), pp 457-484. New York: Wiley.

Crick F, Koch C (1990) Some reflections on visual awareness. Cold Spring Harbor Symp Quant Biol 55:953-962.

Davis RL (1993) Mushroom bodies and Drosophila learning. Neuron $11: 1-14$

Delaney KR, Gelperin A, Fee MS, Flores JA, Gervais R, Tank DW, Kleinfeld D (1994) Waves and stimulus-modulated dynamics in an oscillating olfactory network. Proc Natl $\Lambda$ cad Sci USA, in press.

Dudai Y (1988) Neurogenetic dissection of learning and short-term memory in Drosophila. Annu Rev Neurosci 1 1:537-563.

Dudai Y, Jan Y-N, Byers D, Quinn W, Benzer S (1976) dunce, a mutant of Drosophila deficient in learning. Proc Natl Acad Sci USA 73:1684-1688.

Eckhorn R, Bauer R, Jordan W, Brosch M, Kruse W, Munk M, Reitboeck HJ (1988) Coherent oscillations: a mechanism of feature linking in the visual cortex? Multiple electrode and correlation analyses in the cat. Biol Cybern 60:121-130.

Erber J, Menzel R (1980) Localization of short-term memory in the brain of the bee, Apis mellifera. Physiol Entomol 5:343-358.

Erber J, Homberg U, Gronenberg W (1987) Functional roles of the mushroom bodies in insects. In: Arthropod brain. Its evolution, development, structure and functions (Gupta AP, ed), pp 485-511. New York: Wiley.

Freeman WJ (1972) Measurement of oscillatory responses to electrical stimulation in olfactory bulb of cal. J Neurophysiol 35:762-779.

Freeman WJ (1975) Mass action in the nervous system. New York: Academic.

Freeman WJ (1979) EEG analysis gives model of neuronal templatematching mechanism for sensory search with olfactory bulb. Biol Cybern 35:221-234.

Gelperin A, Tank DW (1990) Odour-modulated collective network oscillations of olfactory interneurons in a terrestrial mollusc. Nature $345: 437-440$

Gerstner W, Ritz R, van Hemmen JL (1993) A biologically motivated and analytically soluble model of collective oscillations in the cortex. Biol Cybern 68:353-374.

Gray CM, Singer W (1989) Stimulus-specific neuronal oscillations in orientation columns of cat visual cortex. Proc Natl Acad Sci USA 86:1698-1702.

Gronenberg W (1987) Anatomical and physiological properties of feedback neurons of the mushroom bodies in the bee brain. Exp Biol $46: 115-125$

Haberly LB (1985) Neuronal circuitry in olfactory cortex: anatomy and functional implications. Chem Senses 10:219-238.

Haberly LB, Bower JM (1989) Olfactory cortex: model circuit for study of associative memory? Trends Neurosci 12:258-264.
Han P-L, Levin LR, Reed RR, Davis RL (1992) Preferential expression of the Drosophila rutabaga gene in mushroom bodies, neura centers for learning in insects. Neuron 9:619-627.

Heisenberg M (1989) Genetic approach to learning and memory (mnemogenetics) in Drosophila melanogaster. In: Fundamentals of memory formation: neuronal plasticity and brain function (Rahmann B, ed), pp 3-45. New York: Fischer.

Heisenberg M, Borst A, Wagner S, Byers D (1985) Drosophila mushroom body mutants are deficient in olfactory learning. J Neurogenet $2: 1-30$.

Homberg $U$ (1984) Processing of antennal information in extrinsic mushroom body neurons of the bee brain. J Comp Physiol [A] 154: $825-836$.

Homberg U, Kingan TG, Hildebrand JG (1987) Immunocytochemistry of GABA in the brain and suboesophageal ganglion of Manduce sexta. Cell Tissue Res 248:1-24.

Homberg U, Montague RA, Hildebrand JG (1988) Anatomy of antenno-cerebral pathways in the brain of the sphinx moth Manduca sexta. Cell Tissue Res 254:255-281.

Homberg U, Christensen TA, Hildebrand JG (1989) Structure and function of the deutocerebrum in insects. Annu Rev Entomol 34:477501 .

Hopfield JJ (1982) Neural networks and physical systems with emergent collective computational abilities. Proc Natl Acad Sci USA 79. 2554-2558.

Kanzaki R, Arbas EA, Strausfeld NJ, Hildebrand JG (1989) Physiology and morphology of projection neurons in the antennal lobes of the male Manduca sexta. J Comp Physiol [A] 165:427-453.

Katz B (1949) Les constantes électriques de la membrane du muscle. Arch Sci Physiol 2:285-299.

Kaulen P, Erber J, Mobbs P (1984) Current source-density analysis in the mushroom bodies of the honeybee (Apis mellifera carnica). $\mathrm{J}$ Comp Physiol [A] 154:569-582.

Kenyon FC (1896) The brain of the bee. A preliminary contribution to the morphology of the nervous system of the arthropoda. J Comp Neurol 6:133-210.

Ketchum KL, Haberly LB (1991) Fast oscillations and dispersive propagation in olfactory cortex and other cortical areas: a functional hypothesis. In: Olfaction. A model for computational neuroscience (Davis JL, Eichenbaum H, ed), pp 69-100. Cambridge, MA: MIT Press.

Kohonen T (1977) A principle of neural associative memory. Neuroscience 2:1065-1076.

Kopell N, LeMasson G (1993) Rhythmogenesis, amplitude modulation and multiplexing in a cortical architecture. In press.

Laurent G, Seymour-Laurent KJ, Johnson K (1993) Dendritic excitability and a voltage-gated calcium current in locust nonspiking local interneurons. J Neurophysiol 69:1484-1498.

Levin LR, Han P-L, Hwang PM, Feinstein PG, Davis RL, Reed RR (1992) The Drosophila learning and memory gene rutabaga encodes a $\mathrm{Ca}^{2+} /$ calmodulin-responsive adenylyl cyclase. Cell 68:479-489.

Livingstone MS, Sziber PP, Quinn WG (1984) Loss of calcium/calmodulin responsiveness in adenylate cyclase of rutabaga, a Drosophila learning mutant. Cell 37:205-215.

Lutz EM, Tyrer NM (1987) Immunohistochemical localization of choline acetyltransferase in the central nervous system of the locust. Brain Res 407:173-179.

Mauelshagen J (1993) Neural correlates of olfactory learning paradigms in an identified neuron in the honeybee brain. J Neurophysiol 69:609-625.

Masson C, Mustaparta H (1990) Chemical information processing in the olfactory system of insects. Part I. Periphery. Physiol Rev 70: $199-245$.

McCormick DA, Pape HC (1990) Properties of a hyperpolarizationactivated cation current and its role in rhythmic oscillations in thalamocortical neurones. J Physiol (Lond) 431:291-318.

Menzel R (1987) Memory traces in honeybees. In: Neurobiology and behavior of honeybecs (Menzel R, Mercer A, cds), pp 310-325. Berlin: Springer.

Menzel R, Erber J, Masuhr T (1974) Learning and memory in the honeybee. In: Experimental analysis of insect behaviour (BartonBrowne, ed), pp 195-217. Berlin: Springer.

Mobbs PG (1982) The brain of the honeybee Apis mellifera. I. The connections and spatial organization of the mushroom bodies. Philos Trans R Soc Lond [Biol] 298:309-354. 
Nighorn A, Healy MJ, Davis RL (1991) The cyclic AMP phosphodiesterase encoded by the Drosophila dunce gene is concentrated in the mushroom body neuropil. Neuron 6:445-467.

Pearson L (1971) The corpora pedunculata of Sphinx ligustri L. and other lepidoptera: an anatomical study. Philos Trans R Soc Lond [Biol] 259:477-516.

Rybak J, Menzel R (1993) Anatomy of the mushroom bodies in the honeybee brain: the neuronal connections of the alpha-lobe. J Comp Neurol 334:444-465.

Schildberger K (1983) Local interneurons associated with the mushroom bodies and the central body in the brain of Acheta domesticus. Cell Tissue Res 230:573-586.

Schildberger K (1984) Multimodal interneurons in the cricket brain: properties of identified extrinsic mushroom body cells. J Comp Physiol [A] 154:71 79 .

Schürmann F-W (1974) Bemerkungen zur Funktion der Corpora pedunculata im Gehirn der Insekten aus morphologischer Sicht. Exp Brain Res 19:406-432.

Schürmann F-W (1987) The architecture of the mushroom bodies and related neuropils in the insect brain. In: Arthropod brain. Its evolu- tion, development, structure and functions (Gupta AP, ed), pp 231264. New York: Wiley.

Sompolinsky H, Golomb D, Kleinfeld D (1990) Global processing of visual stimuli in a neural network of coupled oscillators. Proc Natl Acad Sci USA 87:7200-7204.

Technau G, Heisenberg M (1982) Neural reorganization during metamorphosis of the corpora pedunculata in Drosophila melanogaster. Nature 295:405-407.

Trujillo-Cenóz O, Melamed J (1962) Electron microscope observations on the calyces of the insect brain. J Ultrastruct Res 7:389-398.

Von der Malsburg C, Schneider W (1986) A neural cocktail-party processor. Biol Cybern 54:29-40.

Weiss MJ (1981) Structural patterns in the corpora pedunculata of orthoptera: a reduced silver analysis. J Comp Neurol 203:515-553.

Whithers GS, Fahrbach SE, Robinson GE (1993) Selective neuroanatomical plasticity and division of labour in the honeybee. Nature 364:238-240.

Woolley DE, Timiras PS (1965) Prepyriform electrical activity in the rat during high altitude exposure. Electroencephalogr Clin Neurophysiol 18:680-690. 